$15^{\text {th }}$ International Conference on

AEROSPACE SCIENCES \& AVIATION TECHNOLOGY, ASAT - 15 - May 28 - 30, 2013, Email: asat@mtc.edu.eg, Military Technical College, Kobry Elkobbah, Cairo, Egypt, Tel: +(202) $24025292-24036138$, Fax: + +(202) 22621908

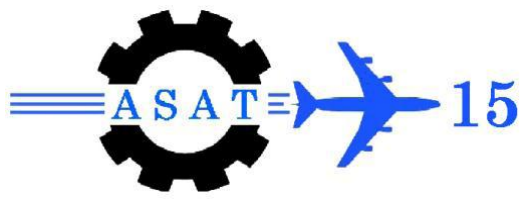

\title{
Experimental Study and Modeling of the Combustion Wave of Metalized Solid Rocket Propellants
}

\author{
Qi-Long Yan ${ }^{*}$, Xiao-Fei Qi ${ }^{\dagger}$
}

\begin{abstract}
The combustion waves of double-base propellants containing reactive metals such as aluminum ( $\mathrm{Al}$ ), magnesium ( $\mathrm{Mg}$ ), boron (B), nickel (Ni) and $\mathrm{Mg}-\mathrm{Al}$ mechanical alloy $(\mathrm{Mg} / \mathrm{Al}=3 / 4)$ has been experimentally investigated by means of thermal couple method. The heat effect of metals in the condensed phase which might control the burning characteristics of the double-base propellant was systematically investigated and descriptions of the detailed combustion physical model of the metals from solid phase to liquid phase or to gas phase are also included. Moreover, a numerical calculation method for analyzing combustion wave structure of metallized propellants has been designed and the fitting functions for the temperature profiles were obtained by Origin 7.5 software. It is believed that in gas phase there would be multi-stage reaction mechanism and that the reaction mechanism would be identical in condensed phase for different metallized propellants, only the heat release value was different.
\end{abstract}

Keywords: propellants; reactive metals; combustion wave; temperature distribution.

\section{Nomenclature}

\begin{tabular}{|c|c|c|c|}
\hline $\mathrm{C}$ & thermal capacity & $\mathrm{P}$ & Pressure \\
\hline$\Delta$ & thermal conductivity & $\Delta H_{v a p-d i s s o c}$ & heat of vaporization-dissociation \\
\hline $\mathrm{N}$ & pressure exponent & $\mathrm{T}$ & Temperature \\
\hline $\mathrm{R}$ & burning rate & $\rho$ & Density \\
\hline $\mathrm{T}$ & Time & $\Phi$ & Diameter \\
\hline$\Lambda$ & thermal conductivity & $\mathrm{k}$ & slope; chemical kinetic parameter \\
\hline $\mathrm{dT} / \mathrm{dx}$ & temperature gradient & $\mathrm{q}$ & sensible heat flux \\
\hline S & surface area & $\mathrm{Z}$ & pre exponential factor \\
\hline$\dot{Q}$ & the rate of heat transfer & $\mathrm{Q}$ & thermal heat release during reaction \\
\hline $\mathrm{c}_{\gamma}$ & the specific heat & $\mathrm{h}$ & the heat transfer coefficient \\
\hline $\mathrm{n}_{\mathrm{p}}$ & pressure exponent & $\mathrm{n}_{\mathrm{i}}$ & ignition parameter \\
\hline$\varepsilon$ & the efficiency factor & & \\
\hline \multicolumn{4}{|c|}{ Subscripts } \\
\hline $\mathrm{G}$ & gas phase & $\mathrm{F}$ & Flame \\
\hline $\mathrm{C}$ & condensed phase & 1 & Liquid \\
\hline $\mathrm{J}$ & $\begin{array}{l}\text { species in condensed } \\
\text { phase }\end{array}$ & $\max$ & Maximum \\
\hline $\mathrm{S}$ & Surface & $\mathrm{i}$ & species in gas phase \\
\hline
\end{tabular}

PhD student, Institute of Energetic Materials, Faculty of Chemical Technology, University of Pardubice, CZ-532 10 Pardubice, Czech Republic; terry.well@163.com or qilongyan@yeah.net.

$\dagger \quad$ Scientific worker, Xi'an Modern Chemistry Research Institute, Xi'an 710065, China; fayeqee@yahoo.com.cn 


\section{Introduction}

Many practical applications have induced continuing interest in metal combustion processes [1-3]. Although metals are generally not considered to be flammable materials because of their high ignition temperatures, they burn extremely vigorously once ignition is achieved. In propulsion systems, however, the combustion of metals typically occurs via small diameter particles which can be either of micro or nano size. One of the most complex aspects of understanding combustion of these propellants is describing the burn physics of the metal particles. Burning metal particles is different than hydrocarbons because of the presence of condensed species. Recently, much research work has been done on the combustion properties of reactive metals and metallized fuels. Prentice and Price have done some experiments on aluminum particle combustion which was aimed at a better understanding of multiple stages in particle combustion, the transition from symmetric to asymmetric particle flames, and particle spinning and jetting $[4,5]$. Meanwhile, magnesium combustion in air has been studied by many researchers for a long time, and it was proposed in the early research, based on the low magnesium boiling point, that the reaction occurs in a vapor phase [6]. Extended vapor phase combustion and condensation zones were clearly observed around burning magnesium particles supporting this hypothesis. Also, several experimental studies dealing with large particles and bulk samples indicated the significance of surface $\mathrm{Mg}-\mathrm{O}$ reactions during the ignition and combustion of magnesium [7-9]. The irregular shape of burning magnesium particles, unusual for metal droplets, was documented previously [10] and attributed to the formation of bulky solid oxide coatings. In addition, as a prime candidate for high enthalpy fuel and propellant formulations due to its potentially high energy release, boron has received much research interest in the past 30 years [11] and most recently, for use in explosive grains, where it might be used to tailor the expansion work of the detonation front. Although boron is traditionally not considered as a real metal, it seems like a metallic element with high melting point and energy content. Moreover, numerous other metals, e.g., iron, molybdenum, nickel and copper, are widely used in combustion synthesis of the structural and electrical materials $[12,13]$.

Though so many achievements on the experimentally study and combustion modeling of metal/oxygen, metal/water and metallized fuels systems have been made [14, 15], with renewed interest in energetic metals, many fundamental issues concerning their practical ignition and combustion characteristics when used as components of solid rocket propellants remain need to be clarified. Furthermore, no data is available on the comparison of some reactive metals that can be most probably used in solid rocket propellants. So in this paper, the research focus will be mainly placed on the establishment of a theoretical description for the combustion wave of double base solid propellant with the presence of micron-sized reactive metals.

\section{Experimental}

\subsection{Materials}

Cyclotrimethylenetrinitramine ( $\mathrm{RDX}, \geq 99.6 \%$ ), nitrocotton $(\mathrm{NC}, \geq 99.5 \%$ ), nitroglycerine $(\mathrm{NG}, \geq 99.2 \%)$, lead phthalate $(\varphi-\mathrm{Pb},>99.5 \%)$, cupric 2,4 -dihydroxybenzoate $(\beta-\mathrm{Cu},>99.8 \%)$ and $\mathrm{N}$-nitrodihydroxyethyl-aminedinitrate (DINA, >99.5\%), 1,3-dimethyl-1,3-diphenyl urea $\left(\mathrm{C}_{2}, \geq 99.0 \%\right.$ ), carbon black (C.B., $>99.8 \%$ ), aluminum ( $\mathrm{Al}, \geq 99.8 \%$ ), nickel $(\mathrm{Ni}, \geq 99.5 \%)$, magnesium ( $\mathrm{Mg}, \geq 99.5 \%$ ), boron $(\mathrm{B}, \geq 99.5 \%)$ and $\mathrm{Mg}_{3} \mathrm{Al}_{4}$ alloy $(\mathrm{Mg} / \mathrm{Al}, \geq 99.6 \%)$ were used as components of double-based propellants. The propellants involved in this study differ only in the type of reactive metals, namely the other components and their ratios were identical. The compositions of the samples involved in this research are presented in detail as follows:1) 
CMDB: NC/26\%; NG/35\%; RDX/36\%; others/3\%; (without metals);2) Al-CMDB: NC/24\%; NG/33\%; RDX/35\%; Al/5\%; others/3\%;3) Mg-CMDB: NC/24\%; NG/33\%; RDX/35\%; $\mathrm{Mg} / 5 \%$; others/3\%;4) B-CMDB: NC/24\%; NG/33\%; RDX/35\%; B/5\%; others/3\%;5) NiCMDB: NC/24\%; NG/33\%; RDX/35\%; Ni/5\%; others/3\%;6) $\mathrm{Mg} / \mathrm{Al}-\mathrm{CMDB}: \mathrm{NC} / 24 \%$; $\mathrm{NG} / 33 \%$; RDX/35\%; (Mg/Al alloys)/5\%; others/3\%. All the samples involved in this investigation, which were prepared by mould process at the temperature of $35^{\circ} \mathrm{C}$ and then solidified for $96 \mathrm{~h}\left(70^{\circ} \mathrm{C}\right)$, were machined to fixed dimension (shape: cylinder; length: $200 \sim$ 250mm; diameter: 5 8mm).

\subsection{Combustion Temperature Profile Test}

The $\Pi$ type double tungsten-rhenium thermocouple was used to test the combustion wave distribution of the solid propellant. The thermocouple $(\Phi=25 \mu \mathrm{m})$ was embedded in the propellant sample (dia., $7 \mathrm{~mm}$; length, $120 \mathrm{~mm}$ ) whose profile was coated by polyvinyl alcohol solvent as a flame-retardant and then exposure to air for drying. The nichrome wire $(\Phi=0.15 \mathrm{~mm})$ with direct-current voltage of $200 \mathrm{~V}$ was adopted for ignition. The automatic trigger acquisition system began to record the data output by the thermocouple after the ignition of the propellant. With the sample burning out, the thermocouple approached the burning surface gradually and finally got into the flame zone (see Fig.2 in ref. [16]). In this way, the whole burning process of the propellant was recorded and the combustion wave from the condensed phase to gas phase was obtained.

\section{Results and Discussion}

\subsection{Metal Particles Characterization}

The particle size distribution is one of the important parameters for characterizations of quality of metal powders. Specific material properties such as ability to flow, reactivity as well as compressibility and its hardening potentials are determined by the size distribution. The metal particle size distribution is a key factor in its atomization processes and other chemical processes such as combustion. The morphology of metal particles can be investigated and quantified by specific surface area measurements and granulometer.

Table 1 summarizes the particle distribution of the metal particles obtained by Malvern laser granulometer and reports the calculated average diameters. Obviously, the dimension of aluminum and boron coincides with the average particle diameter; that means all particles are almost single crystal. But for Al-Mg alloy and $\mathrm{Mg}$, the particle size is larger $(\mathrm{d}(50)>80 \mu \mathrm{m})$ and of wider distribution range, and the particle size of boron is the smallest even arrive at the nano level (around 700nm).

Table 1 The particle size distribution of the metals obtained by laser granulometer

\begin{tabular}{l|ccccccc}
\hline \hline Metal & $\begin{array}{c}\text { refractive } \\
\text { index }\end{array}$ & $\begin{array}{c}\text { Light } \\
\text { block }\end{array}$ & Span & Consistency & $\begin{array}{c}\mathrm{d}(10) / \\
\mu \mathrm{m}\end{array}$ & $\begin{array}{c}\mathrm{d}(50) / \\
\mu \mathrm{m}\end{array}$ & $\begin{array}{c}\mathrm{d}(90) / \\
\mu \mathrm{m}\end{array}$ \\
\hline $\mathrm{Al}$ & 1.780 & $12.43 \%$ & 1.646 & 0.508 & 5.292 & 12.147 & 25.284 \\
$\mathrm{Mg}$ & 1.530 & $23.09 \%$ & 1.146 & 0.350 & 50.462 & 89.351 & 152.820 \\
$\mathrm{Mg} / \mathrm{Al}$ & 1.530 & $5.68 \%$ & 1.132 & 0.354 & 83.269 & 147.555 & 250.237 \\
$\mathrm{~B}$ & 1.630 & $16.82 \%$ & 3.740 & 1.190 & 0.766 & 3.273 & 13.007 \\
$\mathrm{Ni}$ & 1.980 & $9.24 \%$ & 2.160 & 0.665 & 6.699 & 22.558 & 55.424 \\
\hline \hline
\end{tabular}

Notes: Instrument type: Hydro 2000MU(A); Dispersant: Water; Reflex index of the dispersant: 1.330; Granule absorptivity: 0.1; Particle size range: 0.020-2000 
Figure 1 shows the experimental temperature profiles of the combustion wave of modified double-base propellants containing different reactive metal particles at the pressure of $4 \mathrm{MPa}$. $\left(\mathrm{Z}_{\mathrm{f}}\right.$ stand for steady state of combustion zone; $T_{\mathrm{s}}$ stand for the temperature of burning surface; $T_{\mathrm{fm}}$ stand for the minimum temperature of luminous flame; $\mathrm{t}$ stand for the time of preheating; td stand for the time of ignition delay; Criteria for this experiment: the ignition delay can be estimated according to the interval from $T_{\mathrm{s}}$ to the $T_{\mathrm{f}}$ in the temperature profiles and the $T_{\mathrm{s}}$ and $T_{\mathrm{m}}$ are shown in Table 5.)

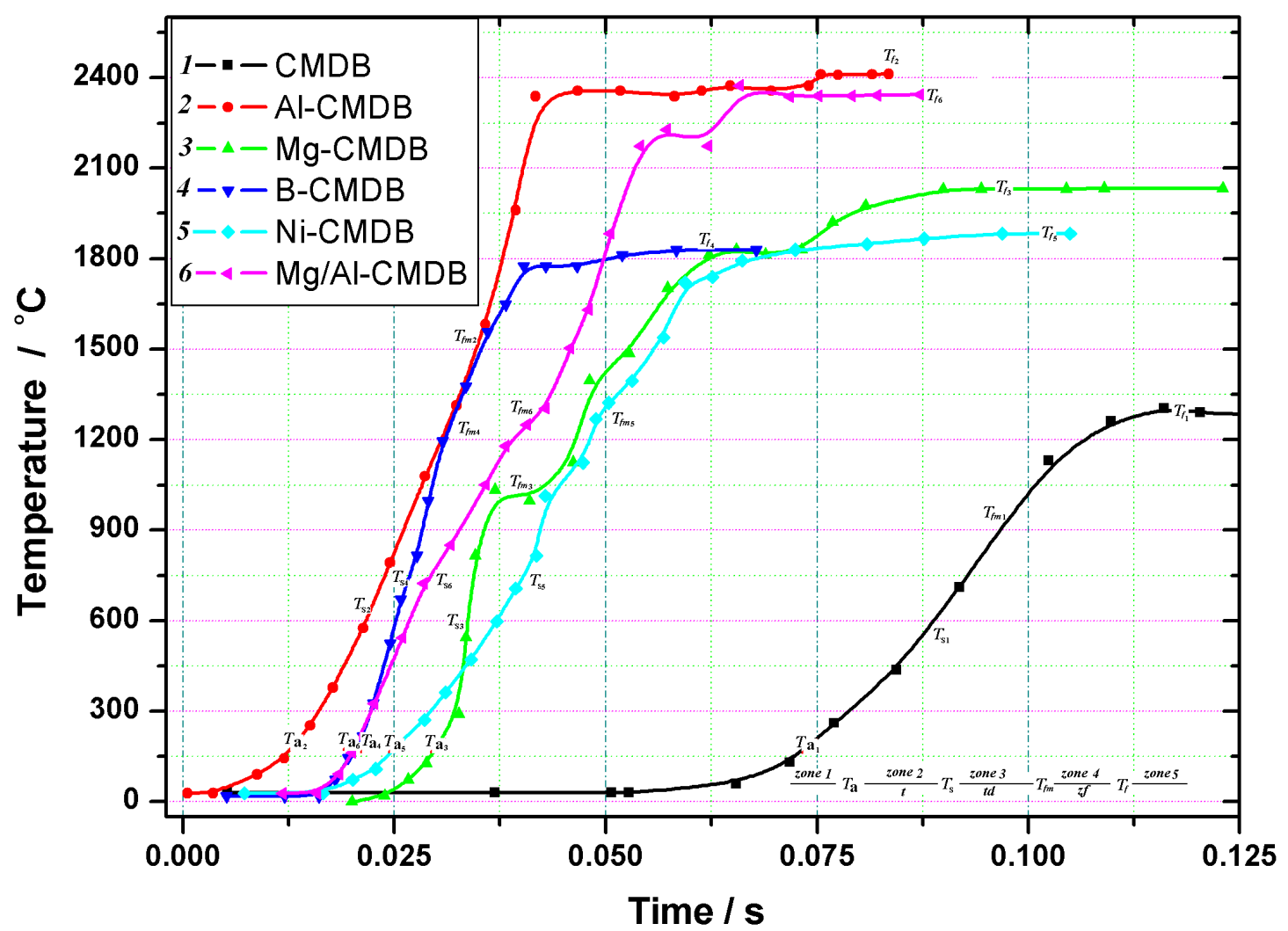

Fig.1 Experimental temperature profiles of the combustion wave of modified double-base propellants containing different reactive metal particles at the pressure of $4 \mathrm{MPa}$.

\subsection{Combustion Wave and Temperature Profiles}

The thermal structure of the combustion wave of double-base propellants containing different metal particles can be understood from the temperature profile traces in their combustion wave (Fig.1). As shown in Fig.1, the temperature in the solid phase increases rapidly from the initial temperature $T_{0}$ to the onset temperature of the solid phase reaction zone $T_{u}$, and the temperature just below the burning surface $T_{\mathrm{s}}$. The temperature continues to increase rapidly from $T_{\mathrm{s}}$ to the temperature at the end of the fizz zone which is equivalent to the beginning of the temperature of the dark zone. Between the dark zone and the flame zone, the temperature increases rapidly again and reaches the maximum flame temperature $T_{\mathrm{f}}$ in the flame zone. It was concluded from Fig. 6 that B-CMDB propellant is of the shortest ignition delay and its burning rate is higher than the other propellants herein at pressure of $4 \mathrm{MPa}$.

According to the actual combustion wave profiles (Fig.1), the temperature gradient increases gradually from the preheated zone to the burning surface and decreases from the burning surface to the stable flame zone. In fact, the temperature profiles from the preheated zone to the flame zone can be approximately composed of two tangent round $\operatorname{arcs}$ (see $R_{1}$ and $R_{2}$ in Fig.2). 


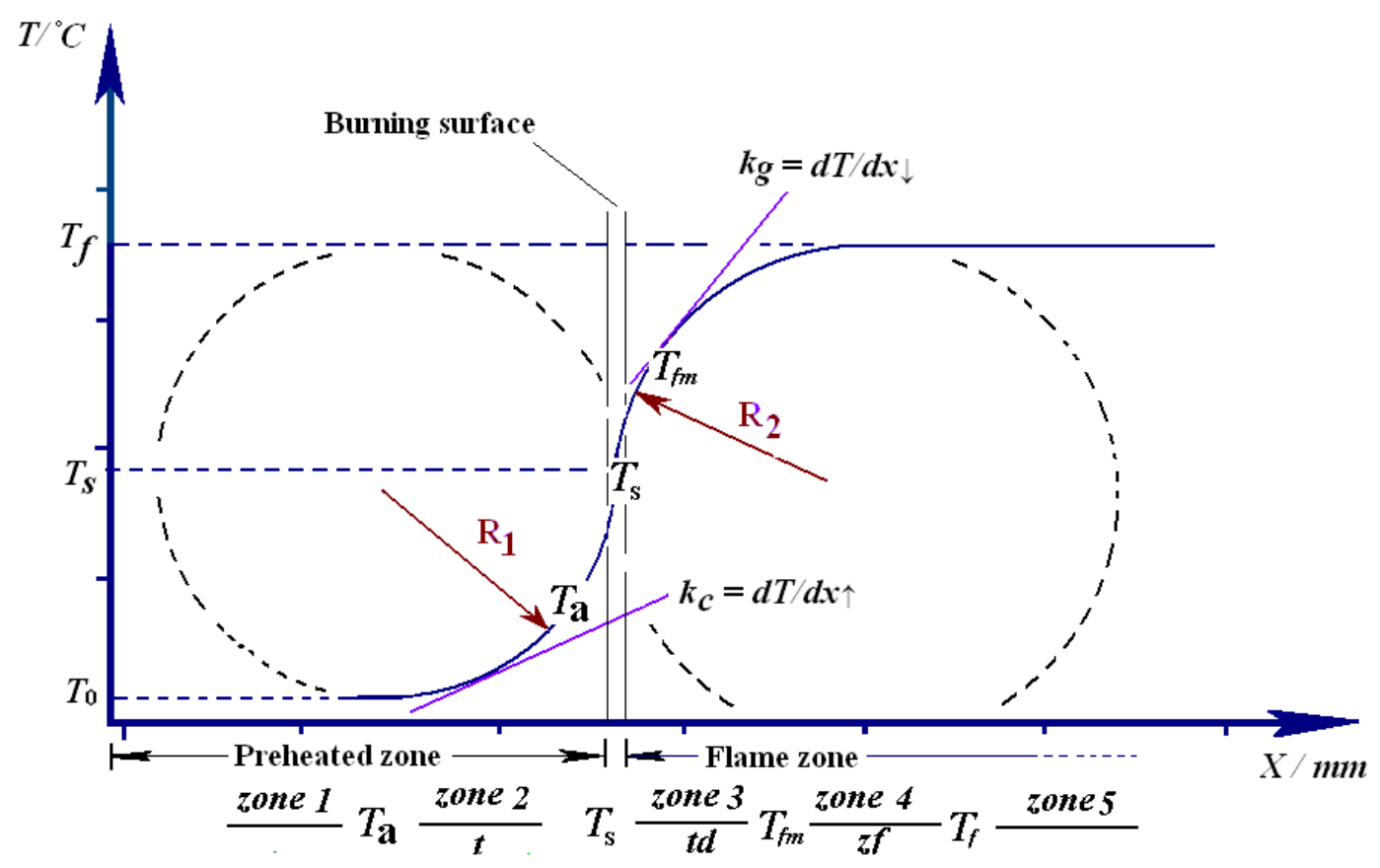

Fig.2 Schematic representations of temperature distributions from the preheated zone to the flame zone in the combustion of metallized solid propellants

As shown in Fig.2, the burning surface is the turning point for the temperature gradient, and the slopes of the tangent $\left(k_{\mathrm{c}}\right.$ and $\left.k_{\mathrm{g}}\right)$ are equivalent to the temperature gradient. From the initial room temperature $T_{0}$ to the maximum flame temperature $T_{\mathrm{f}}$, there are four stages (zones) for the combustion process: with constant room temperature, preheated zone with increasing temperature gradient, dark zone with decreasing temperature gradient and homogeneous flame zone with constant high temperature. For some unsteady state combustion, the temperature profiles may not agree with the common combustion wave model, and the temperature profiles for the combustion of Mg-CMDB, Al-CMDB, and Mg/Al-CMDB (see Fig.6) are typical representations of this kind.

Table 2 The flame temperature distribution parameters obtained by thermocouples*

\begin{tabular}{l|c|c|c|c|c|c|c|c}
\hline \multirow{2}{*}{ Samples } & \multicolumn{4}{|c|}{$1 \mathrm{MPa}$} & \multicolumn{4}{c}{$4 \mathrm{MPa}$} \\
\cline { 2 - 9 } & $\begin{array}{c}\mathrm{T}_{d} / \\
{ }^{\circ} \mathrm{C}\end{array}$ & $\begin{array}{c}\mathrm{T}_{s} / \\
{ }^{\circ} \mathrm{C}\end{array}$ & $\begin{array}{c}\mathrm{d} T / \mathrm{d} x_{\uparrow} \\
\times 10^{4}\end{array}$ & $\begin{array}{c}\mathrm{d} T / \mathrm{d} x_{\downarrow} \\
\times 10^{4}\end{array}$ & $\begin{array}{c}\mathrm{T}_{\downarrow} / \\
{ }^{\circ} \mathrm{C}\end{array}$ & $\begin{array}{c}\mathrm{T}_{s} / \\
{ }^{\circ} \mathrm{C}\end{array}$ & $\begin{array}{c}\mathrm{d} T / \mathrm{d} x_{\uparrow} \\
\times 10^{4}\end{array}$ & $\begin{array}{c}\mathrm{d} T / \mathrm{d} x_{\downarrow} \\
\times 10^{4}\end{array}$ \\
\hline CMDB & 1485 & 587.1 & 1.2754 & 3.4257 & 1671 & 642.1 & 1.6683 & 3.7025 \\
Al-CMDB & 2360 & 702.6 & 2.3547 & 7.2474 & 2483 & 921.3 & 2.6088 & 7.1229 \\
Mg-CMDB & 2310 & 423.5 & 1.1425 & 1.1475 & 2408 & 846.8 & 1.4164 & 1.3212 \\
B-CMDB & 2136 & 671.2 & 1.6845 & 2.3521 & 2385 & 789.2 & 1.9429 & 2.7352 \\
Ni-CMDB & 1820 & 635.7 & 0.7458 & 3.4715 & 2206 & 876.3 & 0.9306 & 3.7816 \\
Mg/Al-CMDB & 2310 & 757.4 & 0.3574 & 2.8475 & 2577 & 984.2 & 0.5734 & 3.1043 \\
\hline
\end{tabular}

*Notes : $T_{\mathrm{s}}$-Temperature of the burning surface $; \mathrm{T}_{\mathrm{f}}-$ maximum flame temperature $; \mathrm{d} T / \mathrm{d} x_{\uparrow}$-temperature gradient of condensed phase at the burning surface $\left({ }^{\circ} \mathrm{C} . \mathrm{mm}^{-1}\right) ; \mathrm{d} T / \mathrm{d} x_{\downarrow}-$ the temperature gradient of gas phase at the beginning of flame zone $\left({ }^{\circ} \mathrm{C} . \mathrm{mm}^{-1}\right)$;

In order to illustrate the accurate structure of their temperature distribution, the detailed data for the combustion wave of modified double-base propellant containing different reactive 
metal particles are obtained and listed in Table 2. It was indicated that the burning surface temperature of $\mathrm{Mg} / \mathrm{Al}-\mathrm{CMDB}$ propellant is high up to $757.4^{\circ} \mathrm{C}$ at $1 \mathrm{MPa}$ and $984.2^{\circ} \mathrm{C}$ at 4 $\mathrm{MPa}$. The temperature gradient of condensed phase at the burning surface from high to low in sequence should be: Al-CMDB > B-CMDB > Mg-CMDB > CMDB > Ni-CMDB > Mg/Al$\mathrm{CMDB}$ (at pressure of $1 \mathrm{MPa}$ and $4 \mathrm{MPa}$ ) and the temperature gradient of gas phase at the beginning of flame zone should be: Al-CMDB > Ni-CMDB > CMDB > Mg/Al-CMDB > BCMDB > Mg-CMDB (at pressure of $1 \mathrm{MPa}$ and $4 \mathrm{MPa}$ ). The enhanced heat transfer to the propellant surface due to large energy release and reduced flame standoff distance in the gas phase at elevated pressure ignoring the influence of preconditioned temperature in determining the energy balance at the surface, and consequently decreases the temperature sensitivity of burning rate. As shown in Table 5, the temperature gradient in condensed phase appears to be lower than that of gas phase (dark zone) $\left(>0.3 \times 10^{4}\right)$, upon that, the temperature of preheating zone changes relatively slowly. In this case, the rate of change in space of the temperature gradient is cannot be ignored in dark zone. Similarly, the rate of mass diffusion is assumed to be large compared with the rate of mass convection.

\subsection{Hypothetical Physical Models for Metal Particle Combustion}

An important difference between the combustion characteristics of hydrocarbon droplets and carbon particles just studied, and of metal particles, is that the combustion products of the former, $\mathrm{H}_{2} \mathrm{O}$ and $\mathrm{CO}_{2}$, are gaseous, while those of the latter are frequently either solid or liquid under the prevailing temperatures. Indeed, it has been suggested that since most metal oxides are refractory in nature, the heat of gasification of the oxide frequently can be so substantial that the flame temperature can be assumed to be at the boiling point of the oxide, as long as some condensed oxide is formed in the flame zone. The motion of the condensed oxides in the flame zone is also of particular interest in that, since they are not subjected to concentration diffusion, they are either convicted or thermophoretically diffused. Consequently, depending on the directions of the Stefan flow in the inner and outer regions to the flame, the net convection can cause these condensed products to be either dispersed to the ambience, or convected toward the droplet surface, or stagnantly trapped at the flame. The fact that the melting points of most metals are lower than those of their respective oxides implies that the oxides are present in condensed phase at the surface of the molten metal particle. These condensed oxides can be either brought in from the flame, or formed when the vapor products condense at the surface, or are originally present over the particle surface. Indeed, all metals exposed to air have a thin film of oxide coating over its surface. The presence of these condensed oxides at the particle surface can affect particle combustion in an essential way. The influence may not be too serious if the particle temperature is higher than the melting point of the oxide, and if the molten oxide can contract under surface tension. The bulk of the molten metal is then exposed to the ambience and, hence, can undergo either gasification or oxidation. If, however, surface tension does not permit contraction, then the metal particle will be covered by the condensed oxide. In such a case reaction is still possible if the molten metal can diffuse through the molten oxide layer to react with the ambient gas, or the ambient gas can diffuse through the layer to react with the metal. Either way, the reaction time is expected to be significantly slowed down due to this diffusional resistance. If the oxide coating is in solid state but is porous, then diffusion of either gas or liquid metal through the pores is still possible, leading to oxidation. However, if the solid coating is nonpermeable, then contact between metal and ambient gas is broken and oxidation could be inhibited.

In our present study, the hypothetical combustion models for metal particles are based on metal particles that are round and have thin neglectable oxide shell. The ignition and 
combustion modes for single micro-sized particles and agglomeration of nano-sized particles are shown in Fig. 3 as follows.

According to the schematic showing of two combustion modes, there are mainly four steps for the metal combustion process due to different particle types. Mode A shows that for a single spherical metal particle which was enwrapped by RDX powder and NC/NG matrix, when temperature increases to the melting point of RDX and NC/NG which are much lower than that of metal particles. The liquid RDX and NC/NG will evenly enwrap and immerge into metal particles as shown in step1; and then the temperature of the metal particles increases greatly and spray into the flame zone by the acutely gas flow as a result of the thermolysis of liquid RDX and NC/NG (step 2); as the temperature arrive at the melting point of the metal, finally the metal begin to react with the gaseous oxidant (step 3). The temperature is increasing and reaches the boiling point of the metals like $\mathrm{Mg}, \mathrm{Al}$ and $\mathrm{Mg} / \mathrm{Al}$, then the liquid metal particles begin to vaporize, the vaporized metal fuel then diffuses outward and reacts with the inwardly diffusing oxidizer gas such as $\mathrm{CH}_{2} \mathrm{O}, \mathrm{NO}_{2}, \mathrm{~N}_{2} \mathrm{O}$ and $\mathrm{HCN}$ at the diffusion flame (step 4). For mode B, the situation is similar, the agglomeration can be considered as a larger spherical metal particle.

If considering the outside oxide shell of metal particles, the oxidation process in the propellant burning process should be described by the melting of the oxide outer layer and the formation of a localized "cap" on the particle surface. The exposed liquid metal particle then evaporates and oxidizes in a gaseous cloud surrounding the particle, and the oxides such as $\mathrm{Al}_{2} \mathrm{O}_{3}, \mathrm{~B}_{2} \mathrm{O}_{3}, \mathrm{NiO}, \mathrm{MgO}$ formed can then diffuse outward or inward to join the cap. Since the phase transition temperatures vary with the chemical composition of atmosphere and pressure, the resulting combustion mechanism is dependent on the oxidizer type and pressure. The transport phenomenon through the condensed and gas phase further complicates the combustion mechanism. Due to the formation of high temperature condensed-phase products, radiation effects also play a role in energy conservation of burning particles. Moreover, inter solubility of metal and its products can also affect the combustion behavior leading to disruption or break up of solid metal.

Hence, the particle temperature will be driven largely by the surrounding environmental temperature. If the environmental temperature is above the vaporization temperature of the metal, the particle will burn through a vapor phase mechanism, although a detached flame will not occur because of the fast transport rates in the surrounding environment. If the environmental temperature is above the melting temperature of the oxide, but not the vaporization temperature of the metal, then the oxide may form a cap on the surface because of the surface tension difference between the molten oxide and metal. Oxidation will occur heterogeneously at the molten metal surface. At still lower environmental temperatures, transport of metal and oxygen through the solid oxide shell with subsequent reaction will dominate.

\subsection{Simulation to the Combustion Wave and Temperature Profiles}

\subsubsection{Model assumption}

The assumed combustion wave structure is similar to that in Fig.1, but, for simplicity, reaction in zone 1 (relatively slow oxidation in solid phase) is neglected, and zone 2 is the fast thermolysis reaction while zone zones 3 and 4 are merged to form the gas phase reaction zone. Thus, the assumed structure of the combustion wave (Fig.2) includes three zones: 
1. Liquid condensed reaction zone (zone 2): $t_{0}<t<t_{\mathrm{a}}, T_{\mathrm{a}}<T<T_{\mathrm{s}}$. No reaction occurs between metal and other components but the fast thermolysis of energetic components takes place. At $\mathrm{z}=0$, where $T_{a}$ is the initial melting point of RDX.

2. Preheat dark zone (zone 3): $t_{\mathrm{a}}<\mathrm{td}<t_{\mathrm{s}}, T_{\mathrm{s}}<T<T_{\mathrm{fm}}$, where $T_{\mathrm{fm}}$ is the minimum luminous flame temperature of metallized propellants (affixed parameter determined experimentally). Gas flows in the interstitial space between particles.

3. Pyrochemical reaction flame zone (zone 4): $t_{\mathrm{s}}<\mathrm{zf}<t_{\mathrm{f}}, T_{\mathrm{fm}}<T<T_{\mathrm{f}}$, where $T_{\mathrm{f}}$ is the maximum adiabatic combustion temperature.

External diffusion-controlled combustion of metal occurs on particle surface in oxidant atmosphere, which implies that the conversion of oxidation on the particle surface is instantaneous and complete, i.e. concentration of oxidants on the particle surface is zero. The influence of formed solid metal oxide on the reaction rate is neglected. Here, the system is assumed to be pseudo-homogenous, so that a single temperature describes both the gas and solid phases. Further model assumptions include constant pressure, neglect of radiation heat transfer and independence of thermal properties with temperature.

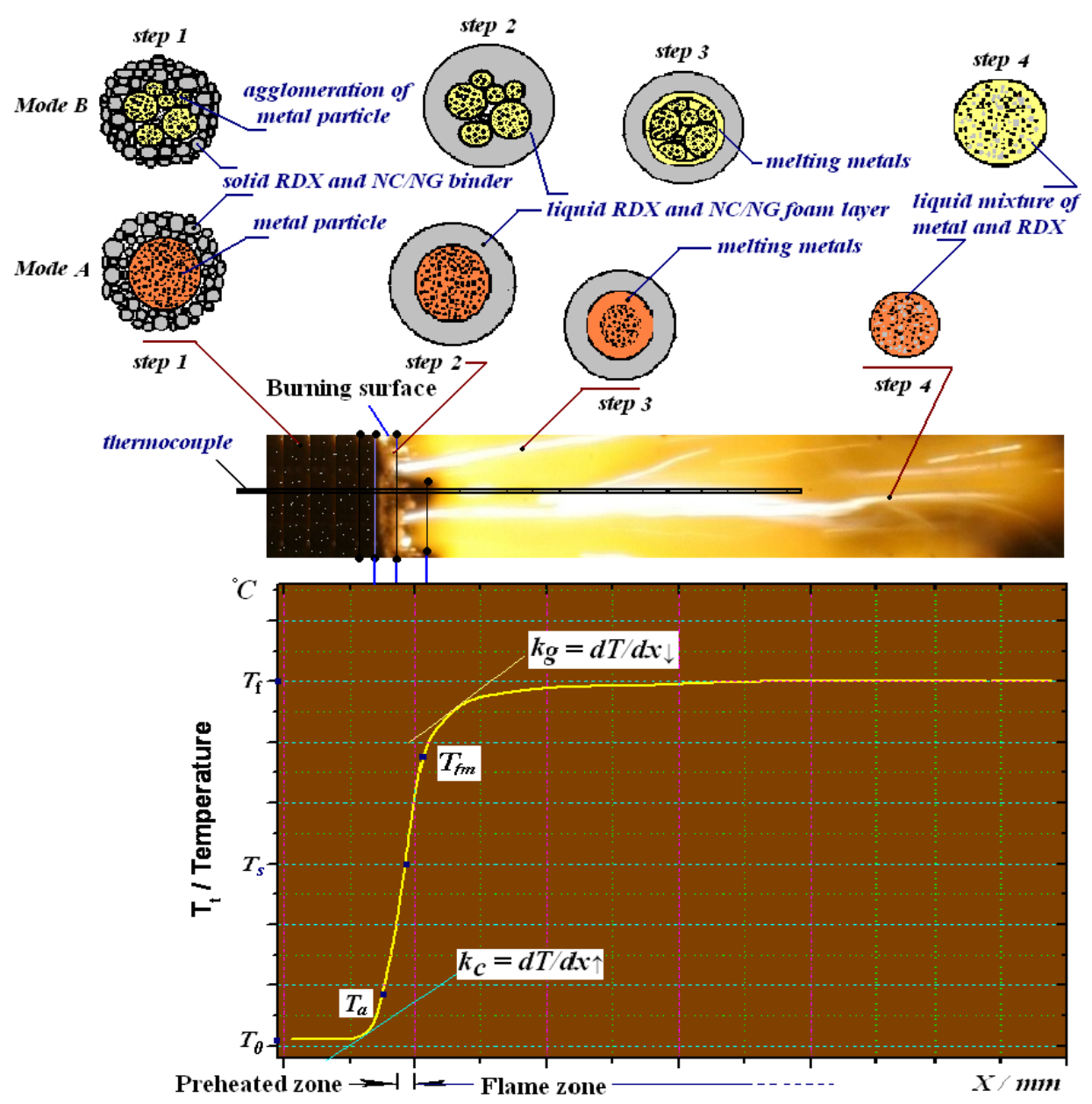

Fig.3 Schematic description of two combustion modes of a spherical metal particle or the agglomeration of metals with less granularity in the modified double-base propellant ignoring the outer oxide layer which is ignorable

(step 1: liquid RDX and binders enwrap the metal particle; step 2: metal particle absorb heat and start to melt; step 3: the temperature is increased fast and the whole metal particle melt and the out layer start to vaporize and decompose; step 4: part of liquid RDX and binders mix with the liquid metal and then high temperature oxidation reaction of the metal particle with the oxidants produced by thermolysis of RDX and binders). 


\subsubsection{Curve fitting for the combustion wave temperature profiles}
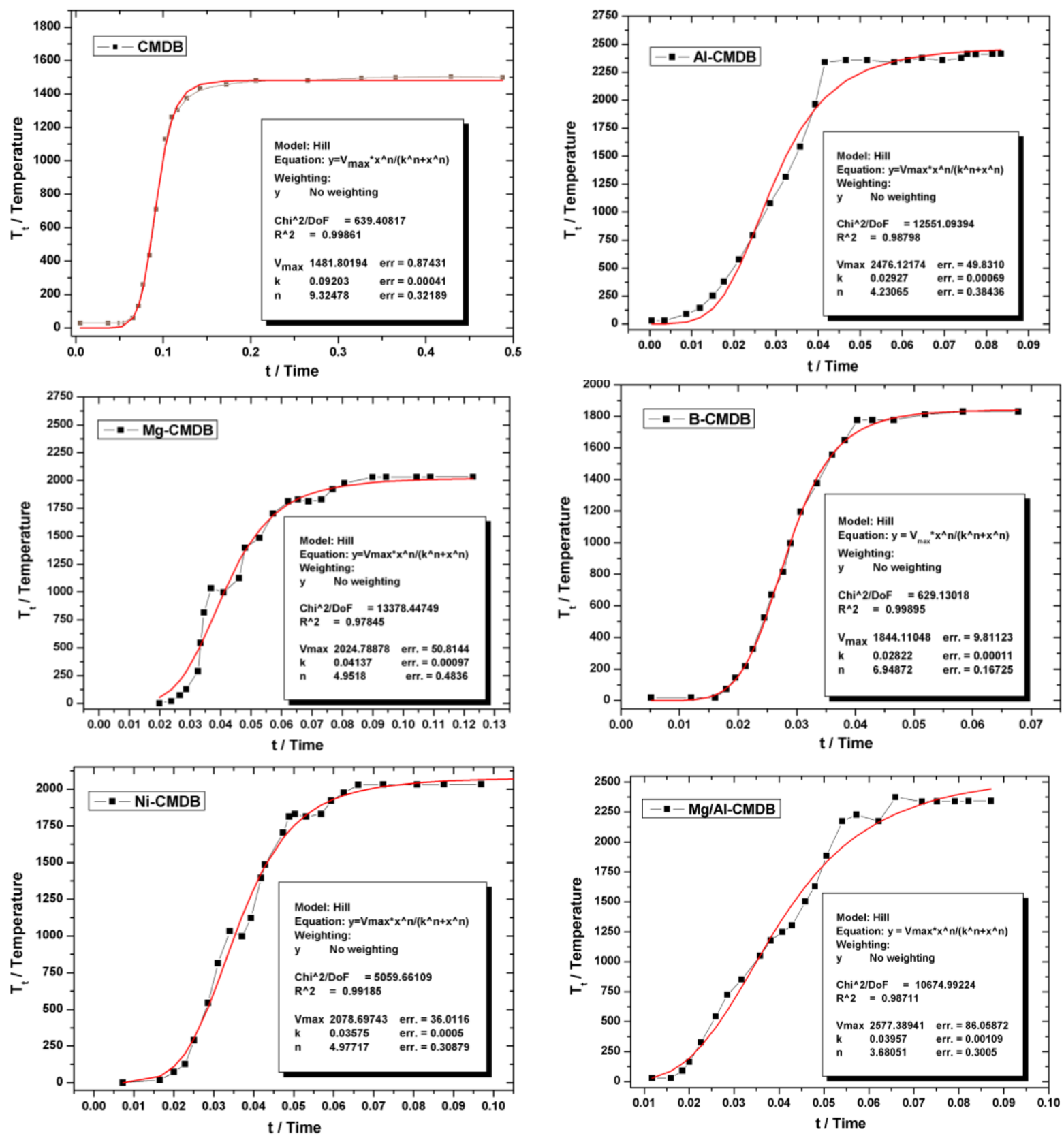

Fig.4 The simulation of the combustion wave curves by the software (Origin 7.5) for data processing (fit model, Hill; simulate by using built-in equation in Origin;

$$
\left.\mathbf{r}>0.9 ; \mathrm{y}=T_{\mathrm{t}} ; \mathrm{V}_{\max } \geq T_{\mathrm{f}}\right)
$$

Before performing linear or nonlinear fitting, the desired experimental combustion wave data were obtained and plotted in Origin 7.5 software created by Origin Lab Corporation, USA. To select a range of a data plot for fitting, click the Data Selector tool on the Tools toolbar to choose the appropriate data. For built-in functions, Origin's NLSF (Nonlinear Least Squares Fitter) uses built-in analytical derivatives for the computation of the derivatives, which is more reliable than straightforward numerical computation of the same derivatives. Herein, a number of built-in functions were tried to fit the experimental temperature profiles, in which the Growth/sigmoidal Hill function was the most appropriate one to fit all of the curves with the pertinent coefficient $\mathrm{R}^{2}$ more than 0.97 . The overall fitting curves are presented in Fig.4. 
An indispensable part of any fitting procedure is a good choice of initial parameter values. The NLSF provides automatic parameter initialization routines for all of the built-in functions [17-19]. The parameter initialization routine for the selected fitting function can be reviewed in the Parameter Initializations dialog box of the NLSF (Scripts: Parameter Initialization).

These routines use the selected dependent and independent data sets to determine appropriate initial parameter values for the selected fitting function. The parameter initialization routine for a selected function is automatically run when you activate the Fitting Session dialog box of the NLSF (Action: Fit). When this dialog box is activated, the Value text boxes display initial values and the graph displays a first guess fit curve in addition to the experimental data.

$$
y=V_{\max } \frac{t^{n}}{k^{n}+t^{n}}
$$

From the fitting results which are summarized in Table 3, it was indicated that the fitting function (1) can satisfy adequately to most of the temperature data of the metallized propellants obtained by the thermocouple especially for the CMDB, B-CMDB and Ni-CMDB propellant. It was further concluded from the fitting results that the combustion process of CMDB, B-CMDB and Ni-CMDB propellants are more stable and homogeneous.

Table 3 Summarization of the fitting parameters for the combustion wave temperature profiles at $4 \mathrm{MPa}$

\begin{tabular}{l|c|c|c|c|c|c|c|l}
\hline \hline \multirow{2}{*}{ Samples } & \multicolumn{8}{|c}{ Function type: $y=V_{\max } \frac{t^{n}}{k^{n}+t^{n}} \ldots \ldots(1)^{*}$} \\
\cline { 2 - 10 } & $\mathrm{V}_{\max }$ & $\begin{array}{c}\text { Error/ } \\
\%\end{array}$ & $k$ & $\begin{array}{c}\text { Error/ } \\
\%\end{array}$ & $n$ & $\begin{array}{c}\text { Error/ } \\
\%\end{array}$ & $\mathrm{R}^{2}$ & $\mathrm{Chi}^{2} / \mathrm{DoF}$ \\
\hline CMDB(a) & 1671.2 & 0.059 & 0.092 & 0.435 & 9.32 & 3.43 & 0.998 & 639.4 \\
Al-CMDB(b) & 2476.1 & 2.011 & 0.029 & 2.414 & 4.23 & 8.98 & 0.988 & 12551.0 \\
Mg-CMDB(c) & 2024.8 & 2.509 & 0.041 & 2.439 & 4.95 & 9.70 & 0.978 & 13378.4 \\
B-CMDB(d) & 1844.4 & 0.532 & 0.028 & 0.357 & 6.95 & 2.45 & 0.998 & 629.1 \\
Ni-CMDB(e) & 2078.7 & 1.732 & 0.036 & 1.389 & 4.98 & 6.22 & 0.992 & 5059.6 \\
Mg/Al-CMDB(f) & 2577.4 & 3.341 & 0.040 & 0.250 & 3.68 & 8.15 & 0.987 & 10675.0 \\
\hline
\end{tabular}

* Notes: $\mathrm{V}_{\max }=$ maximum temperature of the flame $\left(T_{\mathrm{f}}\right) ; k=$ chemical kinetic parameter; $t=$ burning time $(\mathrm{s})$; $n=$ ignition $\operatorname{parameter}\left(n_{i}\right)$;

In order to obtain the combustion wave distribution with the function of distance from the burning surface of the metallized propellants, one can first substitute $\mathrm{V}_{\max }$ and $\mathrm{y}$ in equation (1) by $T_{\mathrm{f}}$ and $T_{\mathrm{t}}$, respectively, then we get

$$
T_{t}=T_{\mathrm{f}} \frac{t^{n_{i}}}{k^{n_{i}}+t^{n_{i}}}
$$

where $T_{\mathrm{f}}$ is the is the maximum adiabatic combustion temperature, $k$ chemical kinetic parameter, $t$ burning time (s); $n_{\mathrm{i}}$ ignition parameter which is an embodiment of ignition pace namely ignition delay. Particularly, the kinetic parameter which can control the combustion reaction rate could be defined as follows;

$$
k=\frac{\varepsilon e^{-E / R T_{f}}}{p}
$$

where $\varepsilon$ is the efficiency factor which relates with the reactive activity of the metals for the metallized propellant, $P$ the ambient pressure, $R$ the standard gas constant and $E$ the activation energy of the propellant. In fact, the equation (4.3-3) is not precise and needs to be further improved and clarified by doing more combustion experiments under a series of pressures in 
our future work. In addition the burning rate $r$ is different from propellant to propellant, so the certain burning time for appointed propellant can be obtained by

$$
t=x / r
$$

When select the solid unreacted propellant interface as the initial state, so the equation (1) can be rewritten as

$$
T_{X}=T_{\mathrm{f}} \frac{\left(\frac{x}{r}\right)^{n}}{\left(\frac{\varepsilon e^{-E / R T_{\mathrm{f}}}}{P}\right)^{n}+\left(\frac{x}{r}\right)^{n}}+T_{0}
$$

where $T_{0}$ is the initial room temperature, $r$ the burning rate of the propellant. For different propellant, the burning rate can be experimentally obtained. According to Table 3 and Table 6 , the combustion wave temperature profiles of the metallized propellants involved herein at 4MPa can be established as follows:

$$
\begin{aligned}
T_{X}(\mathrm{CMDB}) & =1671.2 \times \frac{\left(\frac{x}{13.99}\right)^{9.32}}{0.092^{9.32}+\left(\frac{x}{13.99}\right)^{9.32}}+20 \\
T_{X}(\mathrm{Al}-\mathrm{CMDB}) & =2476.1 \times \frac{\left(\frac{x}{14.26}\right)^{4.23}}{0.029^{4.23}+\left(\frac{x}{14.26}\right)^{4.23}}+20 \\
T_{X}(\mathrm{Mg}-\mathrm{CMDB}) & =2024.8 \times \frac{\left(\frac{x}{12.16}\right)^{4.95}}{0.041^{4.95}+\left(\frac{x}{12.16}\right)^{4.95}}+20 \\
T_{X}(\mathrm{~B}-\mathrm{CMDB}) & =1844.4 \times \frac{\left(\frac{x}{11.29}\right)^{6.95}}{0.028^{6.95}+\left(\frac{x}{11.29}\right)^{6.95}}+20 \\
T_{X}(\mathrm{Mg} / \mathrm{Al}-\mathrm{CMDB}) & =2577.4 \times \frac{\left(\frac{x}{10.68}\right)^{4.98}}{0.040^{3.68}+\left(\frac{x}{13.15}\right)^{3.68}}+20 \\
T_{X}(\mathrm{Ni}-\mathrm{CMDB}) & =2078.7 \times \frac{\left(\frac{x}{13.15}\right)^{3.68}}{0.041^{4.98}+\left(\frac{x 8}{10.68}\right.}+20
\end{aligned}
$$


where $x$ is in mm and $T_{\mathrm{x}}$ in degree centigrade. From the equations (6) (11) mentioned above, the detailed temperature at a certain point in the combustion zone for different metallized propellants could be easily obtained.

\subsubsection{Heat release in different combustion zones}

In order to gain a fundamental understanding of the heat feedback process in the gas phase, a heat release in the gas phase is assumed to be given by a step function and has a positive constant value. The heat model represents the heat flux from the condensed to the phase gas phase should be

$$
\lambda_{p} \frac{d^{2} T}{d x^{2}}-\rho_{p} c_{p} r_{p} \frac{d T}{d x}=\dot{q}
$$

where $\dot{q}$ is the heat release rate, $\lambda_{p}$ the thermal conductivity, $r$ the burning rate, $\rho_{p}$ the density of the propellant, and $C_{p}$ thermal capacity. Moreover, the differential equation of (5) namely

$$
\frac{d T}{d x}=T_{\mathrm{f}}\left(\frac{\varepsilon e^{-E / R T_{\mathrm{f}}}}{P}\right)^{n} \frac{n\left(\frac{x}{r}\right)^{n-1}}{r\left[\left(\frac{\varepsilon e^{-E / R T_{\mathrm{f}}}}{P}\right)^{n}+\left(\frac{x}{r}\right)^{n}\right]^{2}}
$$

is defined as temperature gradient. In fact, according to Fig.2, the temperature gradient has a maximum value in the range of the combustion wave. In order to obtain the accurate position of the interface between condensed phase zone and the flame zone (including the dark zone), we can further differentiate the function of temperature gradient as follows;

$$
\frac{d^{2} T}{d x^{2}}=n T_{\mathrm{f}}\left(\frac{x}{r}\right)^{n-2}\left(\frac{\varepsilon e^{-E / R T_{\mathrm{f}}}}{P}\right)^{n} \frac{\square n-1 \square\left(\varepsilon P e^{-E / R T_{\mathrm{f}}}\right)^{n}-(n+1)\left(\frac{x}{r}\right)^{n}}{r^{2}\left[\left(\frac{\varepsilon e^{-E / R T_{\mathrm{f}}}}{P}\right)^{n}+\left(\frac{x}{r}\right)^{n}\right]^{3}}
$$

Based on the equations (12) and (13), the heat release rate in the burning surface could be obtained by equation (11). In addition, if

$$
\frac{d^{2} T}{d x^{2}}=0, \text { namely }(n-1)\left(\frac{\varepsilon e^{-E / R T_{\mathrm{f}}}}{P}\right)^{n}-(n+1)\left(\frac{x}{r}\right)^{n}=0
$$

thereby

$$
x_{0}=r \frac{\varepsilon e^{-E / R T_{\mathrm{f}}}}{P} \sqrt[n]{\frac{n-1}{n+1}}=r k \sqrt[n]{\frac{n-1}{n+1}}
$$

Then the maximum value of the temperature gradient could be obtained by substituting $x$ with $x_{0}$ in equation (12), where $x_{0}$ is the thickness of the dark zone. According to Table 2, the thickness of the condensed phase of CMDB, Al-CMDB, Mg-CMDB B-CMDB, Ni-CMDB, $\mathrm{Mg} / \mathrm{Al}-\mathrm{CMDB}$ propellants at $4 \mathrm{MPa}$ are $1.26 \mathrm{~mm}, 0.37 \mathrm{~mm}, 0.46 \mathrm{~mm}, 0.30 \mathrm{~mm}, 0.35 \mathrm{~mm}$, and $0.45 \mathrm{~mm}$, respectively. Based on these data, the temperature of the burning surface $\left(T_{\mathrm{s}}\right)$ for all propellants could be obtained by the equation (5) as $681.4^{\circ} \mathrm{C}, 965.4^{\circ} \mathrm{C}, 827.9^{\circ} \mathrm{C}, 809.5^{\circ} \mathrm{C}$, $850.6^{\circ} \mathrm{C}$, and $958.5^{\circ} \mathrm{C}$ in sequence, respectively, which are in good agreement with the results obtained by the thermocouple (see Table 2). 


\section{Conclusions}

The characteristics of metal particles, three stages of combustion and physical model for metal particles have been illustrated and discussed in detail. Micron-sized particle combustion is characterized by some well-known features such as brightness oscillations, disruptive burning, burning droplet speed variations, oxydant gases build-up within the molten particle, and asymmetric combustion. It has been found that metal combustion can occur either heterogeneously at the particle surface or homogeneously in the surrounding gaseous environment. The temperature of the burning surface $\left(T_{\mathrm{s}}\right)$ for all propellants could be obtained by the theoretical model, which is in good agreement with the results obtained by the thermocouple. Theoretical calculation by the deduced model, metallized propellant is subject to have thinner condensed phase zone than that of blank propellant.

\section{Acknowledgement}

Special thanks to Wang Ying, who obtained the temperature profiles from the combustion experiments. The authors also thank Dr. Li Xiao-Yu and Dr. Wang Ke-Yong for their help in design and construction of the experimental setups. The assistance of Dr. Li Ji-Zhen in preparation of experimental samples is also gratefully acknowledged.

\section{References}

[1] Richard A. Yetter, Grant A. Risha, Steven F. Son, Metal particle combustion and nanotechnology, Proceedings of the Combustion Institute 32 (2009) 1819-1838.

[2] E.L. Dreizin, Phase changes in metal combustion, Progress in Energy and Combustion Science 26 (2000) 57-78.

[3] Davis, A., Solid Propellants: The Combustion of Particles of Metal Ingredients, Combustion and Flame, Vol. 7, 1963, pp. 359-367.

[4] Prentice JL. (Ed.), Combustion of pulse-heated single particles of aluminum and beryllium. NWC TP 5162, Naval Weapons Center, China Lake, CA, 1971.

[5] Price EW. In: Kuo KK, Summerfield M, editors. Fundamentals of solid propellant combustion. New York: AIAA, 1984. p. 479-514.

[6] Brzustowski TA, Glassman I. In: Wolfhard HG, Glassman I, Green L, editors. Heterogeneous combustion. New York: Academic Press, 1964. p. 75-115.

[7] Takeno T, Yuasa S. Ignition of Magnesium and Magnesium-Aluminum Alloy by Impinging Hot-Air Stream, Combustion Science \& Technology, 1980; 21:109-21.

[8] Fassel WM, Papp CA, Hildenbrand DL, Sernka RP. In: Summerfield M, editor. Solid propellant rocket research, New York: Academic Press, 1960.

[9] Dreizin, Edward L. ; Hoffmann, Vern K. Constant pressure combustion of aerosol of coarse magnesium particles in microgravity, Combustion and Flame 1999, Vol.118,No.1. p. 214-19.

[10] Yuriy L. Shoshin, Ruslan S. Mudryy, Preparation and Characterization of Energetic AlMg Mechanical Alloy Powders, Combustion and Flame, (2002)128:259-269.

[11] King, M. K., the Combustion of Boron-Based Solid Propellants and Soild Fuels (K. K. Kuo and R. Pein, Eds.), Begell House Publishing Co. and CRC Press, Inc., Boca Raton, 1993, pp. 1-80.

[12] Foiles, S. M., Calculation of the surface segregation of $\mathrm{Ni}-\mathrm{Cu}$ alloys with the use of the embedded-atom method, Physical Review B, 1985, Vol. 32, No. 12, pp. 7685-7693.

[13] E. Shafirovich, P. Escot Bocanegra, C. Chauveau,et al, Ignition of single nickel-coated aluminum particles, Proceedings of the Combustion Institute 30 (2005) 2055-2062. 
[14] Eck, B., Kurtulus, Y., Offermans, and W., Dronskowski, R., Atomistic Simulations of Solid-State Materials Based on Crystal-Chemical Potential Concepts: Application for Compounds, Metals, Alloys, and Chemical Reactions. Journal of Alloys and Compounds, Vol. 338, 2002, pp. 142.

[15] Johnson, C., Parr, T., Hanson-Parr, D., Hollins, R., Fallis, S., and Higa, K., "Combustion and Oxidation of Metal Nanoparticles and Composite Particles," Proceedings of 37th JANNAF Meeting, 13-17 Nov, 2000, pp. 539.

[16] Qi-Long Yan, Zhen-Wei Song, Xiao-Bing Shi, et, al. Combustion mechanism of double-base propellant containing nitrogen heterocyclic nitroamines (II): The temperature distribution of the flame and its chemical structure, Acta Astronautica 64 (2009) 602-614.

[17] C F Mallery et al, Further Improvments to FTIR Absorption Spectroscopy of Propellant Flames for Profiling of Species and Temperature (A). Proceedings of 32nd JANNAF Combustion Subcommitte Meeting [C], pp.449, 1995.

[18] A A Zenin, Thermophysics of Stable Combustion Waves of Solid Propellants [A]. Nonsteady Burning and Combustion Stability of Solid Propellants [C], edited by Luigi De Luca, E.W.Price,M.Summerfield,Vol.143, Progress in Astronautics and Aeronautics, AIAA, 1992, Chap.6.

[19] M S Miller. An Evaluation of Imbedded Thermal Couples as a Solid Propellant Combustion Diagnostic [P].ADA 219947, 1990. 